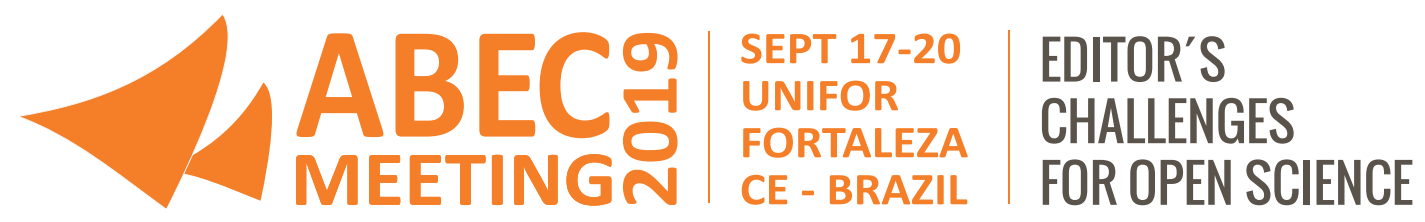

\title{
HISTÓRIA DE UM PERIÓDICO DA SAÚDE: DESAFIOS E TRANSFORMAÇÕES INOVADORAS
}

History of a health journal: Challenges and innovative transformations

\author{
Paula Borges Jacques ${ }^{1}$ \\ Ana Elizabeth Gondim Gomes ${ }^{2}$ \\ Fernanda Gadelha Severino ${ }^{3}$ \\ Raquel Cristina de Sousa Lima Landim ${ }^{4}$ \\ Guilherme Pinheiro Ferreira da Silva ${ }^{5}$ \\ Liza Barreto Vieira ${ }^{6}$ \\ Maria Albertina Rocha Diógenes ${ }^{7}$ \\ Juliana Maria de Sousa Pinto ${ }^{8}$ \\ Paulo Rafael Nogueira Pontes ${ }^{9}$
}

\section{COMO CITAR}

JACQUES, Paula Borges et al. História de um periódico da saúde: desafios e transformações inovadoras. In: ABEC Meeting, 2019, Fortaleza. Anais... São Paulo: Associação Brasileira de Editores Científicos, 2019. http://dx.doi.org/10.21452/abecmeeting.2019.213

\section{RESUMO}

O objetivo é apresentar uma breve história da Revista Brasileira em Promoção da Saúde - RBPS, iniciada em 1984 como Revista do Centro de Ciências da Saúde, que, ao longo dos anos, sofreu mudanças impactantes no que se refere à sua abrangência, escopo e relevância para a área da promoção da saúde. Foi reapresentada à comunidade científica em 2003, renomeada para RBPS, enviada para análise de bases e indexadores nacionais e internacionais, tornando-se bilín-

\footnotetext{
1 Editora-chefe da Revista Brasileira em Promoção da Saúde, Universidade de Fortaleza, Fortaleza, Ceará, Brasil. 2 Editor-científico da Revista Brasileira em Promoção da Saúde, Universidade de Fortaleza, Fortaleza, Ceará, Brasil. ${ }^{3}$ Editor-científico da Revista Brasileira em Promoção da Saúde, Universidade de Fortaleza, Fortaleza, Ceará, Brasil. ${ }^{4}$ Editor-científico da Revista Brasileira em Promoção da Saúde, Universidade de Fortaleza, Fortaleza, Ceará, Brasil. ${ }^{5}$ Editor-científico da Revista Brasileira em Promoção da Saúde, Universidade de Fortaleza, Fortaleza, Ceará, Brasil. ${ }^{6}$ Editor-científico da Revista Brasileira em Promoção da Saúde, Universidade de Fortaleza, Fortaleza, Ceará, Brasil. 7 Editor-científico da Revista Brasileira em Promoção da Saúde, Universidade de Fortaleza, Fortaleza, Ceará, Brasil. ${ }_{8}$ Conselho Superior de Editoração da Universidade de Fortaleza, Fortaleza, Ceará, Brasil. ๑ Secretário da Revista Brasileira em Promoção da Saúde, Universidade de Fortaleza, Fortaleza, Ceará, Brasil.
} 
gue em 2015, ampliando assim, o número de leitores e de submissão de trabalhos. Novas mudanças quanto ao número de artigos publicados e ainda, tornar-se publicação contínua, contribuíram para que a RBPS pudesse ser um periódico de escolha para a área de promoção da saúde.

\section{PALAVRAS-CHAVE}

Publicação Periódica; Promoção da saúde; Publicações; Editoração.

\section{ABSTRACT}

The objective is to present a brief history of the Brazilian Journal on Health Promotion - RBPS, started in 1984 as a Journal of the Health Sciences Center, which, over the years, has undergone significant changes in its scope, scope and relevance. for health promotion. It was re-presented to the scientific community in 2003, renamed RBPS, sent for analysis of national and international databases and indexers, becoming bilingual in 2015, thus increasing the number of readers and submitting papers. New changes in the number of articles published and also, becoming a continuous publication, contributed to the RBPS could be a journal of choice for the health promotion area.

\section{KEYWORDS}

Periodical; Health Promotion; Publications; Publishing.

\section{SIINTESE DOS DADOS}

Um periódico nasce de um desejo e da ânsia de pessoas entusiamadas em contribuir com o conhecimento científico, amparadas na organização e no apoio de uma instituição, focando em leitores específicos e motivados com inovações. Assim, iniciou-se a Revista Brasileira em Promoção da Saúde, fundada em 1984 como Revista do Centro de Ciências da Saúde - RECCS, tendo como foco inicial contribuir para a disseminação do conhecimento por meio da produção científica realizada nos cursos do Centro de Ciências da Saúde da Universidade de Fortaleza. "Nasceu e floresceu com uma timidez circunscrita a imposição do nome registrado. Mesmo assim, percorreu caminhos com idas e vindas, passando por etapas de aprendizagem e de ensinamento, construiu um processo valioso de formação e/ou de mudança de hábito de escrever e de publicar trabalhos. Todos passaram a ler o periódico. No decorrer do tempo, com o trabalho sistemático, com caminho de princípio e fim determinados, passou-se, gradativamente, em uma longa labuta de anos, envolver mais e mais atores na construção e elaboração da Revista." (OLINDA; SILVA; MONTENEGRO JUNIOR, 2005.).

No ano de 2003 houve uma grande mudança na RECCS, no intuito de crescer e de ser atraente para um maior público além fronteiras da Universidade, do Ceará e do Nordeste. (Re)nascia, desta forma, como RBPS, atrevidamente intitulando-se com brasileira, expandindo seu horizonte e centralizada em um tema abrangente, completo e inclusivo, conforme atestam Olinda, Silva e Montenegro Junior (2005): "a feliz denominação do Periódico que definiu o público leitor, em especial, todos os profissionais que fazem Saúde Pública, os que promovem a saúde, previnem a doença e cura os males das pessoas. Eternos benfeitores da humanidade." 
De cinco artigos publicados em seu primeiro número em 1984 como RECCS, aos 80 publicados atualmente por ano, todos bilíngues, com resumo traduzidos em inglês e em espanhol, publicação contínua e em pdfA, a RBPS atravessou uma longa história permeada por imensos desafios vencidos por todos aqueles que a geriram. Dos textos recebidos gravados em "disquetes", pelo correio, pelos editores, para a editoração eletrônica atual no sistema OJS, passando pelos textos recebidos em formato de "CD", em seguida pelo recebimento via e-mail, gravados em word, quando se olha para trás é que se percebe a intensidade de sua história.

Nos anos de 2004 a 2006, publicavam-se nesta RBPS quatro números, contendo editorial e oito artigos cada, nas modalidades artigos originais, artigos de revisão, descrição ou avaliação de experiências, métodos, técnicas, procedimentos e instrumentais e relatos de casos. Os artigos eram publicados na língua portuguesa, e caso fossem recebidos em inglês ou espanhol, eram publicados desta forma. Também se iniciou, nesta época, a submissão da RBPS para avaliação em bases e indexadores, nacionais e internacionais. Os números 3 e 4 de 2006 sofreram aumento gradual do número de artigos publicados, passando-se a dez artigos.

Em 2008, iniciaram-se, na Universidade de Fortaleza, os treinamentos com os editores e secretários de seus seis periódicos, para a inserção dos mesmos em sistemas de editoração eletrônica, por meio do Conselho Superior de Editoração. E gradualmente, todos puseram-se ao trabalho de digitalização de seus arquivos e iniciação em plataforma eletrônica de publicação científica.

Outro aumento do número de artigos ocorreu em 2010, passando-se a doze por número, sendo publicados 48 artigos. Em 2011, aumentou-se para 16 artigos por número, sendo representativo do expressivo aumento de entrada de novas submissões no sistema eletrônico da RBPS, objetivando-se um futuro desejado quanto ao número de artigos publicados de acordo com a área da saúde, para que pudesse ser (bem) avaliada por novas bases e indexadores.

O ano de 2013 foi marcado pela internacionalização da RBPS, por meio da publicação obrigatória em português e em inglês, além do aumento, uma vez mais, do número de artigos para 18 por número, totalizando-se 72 artigos e o editorial.

A maior busca de leitores em publicar nesta RBPS sempre foi motivo de grande orgulho, por parte de todos os Editores que a gerenciaram e que fazem parte de sua memória. 0 aumento do número de leitores, de visualizações e de citação dos artigos serviu para evidenciar-se a qualidade científica de suas publicações encorajando-se, desta forma, o envio da RBPS para bases nacionais, como o LILACS, na qual está indexada há alguns anos. Atualmente, a RBPS encontra-se em 22 indexadores e bases nacionais e internacionais.

Em 2014 foi lançado o primeiro suplemento advindo de um evento científico, e o ano foi caracterizado por ter publicado seus quatro números e um suplemento, honrando-se a RBPS como periódico de escolha para disseminar a produção e a descoberta científica de artigos/resumos de trabalhos apresentados em um encontro específico, que tivesse relação com o escopo da revista. Em 2016, houve a primeira publicação de um evento internacional nas páginas da RBPS, como suplemento, o qual é realizado periodicamente. Este ano também representa um marco para a publicação em formato apenas eletrônico.

Nova alteração no número de artigos publicados ao ano ocorreu em 2018, quando o layout e a forma de apresentação sofreram modificações, para que o artigo pudesse ficar mais colorido e 
visualmente atraente, além de estar adequando-se a RBPS para análise em novos indexadores, seguindo os critérios por eles desejados. Também houve nova reformulação no quadro de editores internacionais e nacionais, vislumbrando-se estar de acordo com o desejado pelos indexadores.

Seguindo-se o curso da história, a RBPS chega ao ano de 2019 completando 35 anos de existência, alterando seu fluxo para publicação contínua, melhora na tecnologia passando a publicar em pdfA, bilíngue, acesso aberto e eletrônico, cuja equipe base é formada por uma editora-chefe, seis editores científicos e um secretário, apoiada pelo Conselho Superior de Editoração e pelo Centro de Ciências da Saúde da Universidade de Fortaleza. Recebeu recentemente o certificado de indexação no Redalyc 2020, atestada por sua qualidade editorial e científica, tecnologia de publicação digital XML-JATS e política de acesso aberto, entre outros. Opera via sistema Open Journal Systems (OJS 2.4.8.1), apresenta cerca de 290 novas submissões até o momento, contando com quase 460 avaliadores ad-hoc, 38 participantes no comitê editorial nacional e 18 do comitê internacional. Tais representantes de excelência são de extrema importância para a RBPS.

Assim, a RBPS, de pequena almeja fazer-se grande, trilhar novos passos e novos desafios, alicerçada em sua missão de "fomentar o desenvolvimento da Promoção da Saúde/Saúde Coletiva por meio da publicação cientifica advinda de ações e pesquisas de relevância e correlação com estas áreas" e nas "práticas internacionais de publicação científica, acelerando a comunicação e os resultados de pesquisas."

\section{REFERÊNCIAS}

OLINDA, Q.B.; SILVA, C.A.B. da; MONTENEGRO JUNIOR, C. R. Como se gesta um periódico. Revista Brasileira em Promoção da Saúde, Fortaleza, v. 18., n. 1, 2005. p. 1-2. Disponível em: https://periodicos.unifor.br/rbps. Acesso em: 28.08.2019.

REVISTA BRASILEIRA EM PROMOÇÃO DA SAÚDE. Disponível em: https://periodicos.unifor.br/rbps. Acesso em: 29.08.2019. 